\title{
Criptococose pulmonar associada à infecção sistêmica por Corynebacterium pseudotuberculosis em cabra (Capra hircus)
}

\author{
Pulmonary cryptococcosis associated with systemic infection by Corynebacterium pseudotuberculosis \\ in a goat (Capra hircus)
}

\author{
Laura Iglesias de Oliveira, IV Juliana da Silva Prado ${ }^{\mathrm{II}}$ Bernardo Melo da Cunha ${ }^{\mathrm{III}}$ \\ Ticiana Nascimento França ${ }^{\mathrm{IV}}$ Luiz Fabio de Oliveira da Rocha ${ }^{\mathrm{III}}$ Renata Lins Carrocino ${ }^{\mathrm{III}}$ \\ Marilene de Farias Brito ${ }^{\mathrm{IV}}$
}

- NOTA -

\section{RESUMO}

Descreve-se presença de lesão pulmonar em cabra (Capra hircus) sugestiva de criptococose. O cultivo bacteriológico realizado a partir de material purulento articular revelou concomitante infecção por Corynebacterium pseudotuberculosis. À microscopia óptica observaram-se estruturas leveduriformes nos espaços alveolares do pulmão, dotadas de espessa cápsula de polissacarídeos PAS positivas, compatíveis com Cryptococcus spp. Casos de criptococose em caprídeos são considerados raros na literatura. Objetiva-se relatar os aspectos epidemiológicos e clínico-patológicos da forma pulmonar de infecção por Cryptococcus spp. em uma cabra no Brasil.

Palavras-chave: caprino, Cryptococcus spp., Corynebacterium pseudotuberculosis.

\section{ABSTRACT}

An infection by Cryptococcus spp. in a goat (Capra hircus) is reported. The bacterial culture performed from purulent material collected from joint abscesses revealed concomitant infection by Corynebacterium pseudotuberculosis. Optical microscopy revealed yeast-like structures in the alveolar spaces of the lungs, exhibiting a thick, PAS positive, polysaccharide capsule compatible with Cryptococcus spp. Cases of cryptococcosis in goats are considered rare in the literature. The objective is to describe the epidemiological and clinical-pathological aspects of the pulmonary form of an infection by Cryptococcus spp. in a goat in Brazil.

Key words: Goat, Cryptococcus spp., Corynebacterium pseudotuberculosis.
Cryptococcus spp. é um fungo que apresenta mais de 30 espécies descritas (BIVANCO et al., 2006). Sua cápsula polissacarídica é um dos mais importantes fatores de virulência (CHANG \& KWONCHUNG 1994; LIN, 2009) e a observação de sua imagem negativa é utilizada no diagnóstico citológico e histopatológico em colorações como o ácido periódico de Schiff(PAS) (CASWELL \& WILLIAMS, 2007). Pode ser isolado de amostras de solo que contenha material orgânico, vegetais em decomposição, frutos e excrementos de aves, principalmente columbíferos (BERNARDO et al., 2001).

A infecção fúngica já foi descrita no homem (BERNARDO et al., 2001; PAPPALARDO \& MELHEM, 2003) e em diversas espécies animais, tais como mamíferos, pássaros, répteis e invertebrados (TORRESRODRIGUEZ et al., 2006) e, em geral, ocorre por inalação de poeira contaminada com conídios fúngicos (CASWELL \& WILLIAMS, 2007; TORRESRODRIGUEZ et al., 2006). O micro-organismo tem forte afinidade pelo cérebro e meninges e é passível de disseminação pelos turbinados ou por via hematógena (JONES et al., 2000). Além do tropismo pelo sistema respiratório, sistema nervoso central e tegumentar, tem sido isolado de mastite em bovinos (LANGONI et al.,

'Universidade Estácio de Sá, 21820-096, Rio de Janeiro, RJ, Brasil. E-mail: laurinhaiglesias@ gmail.com. Autor para correspondência. IIPrograma de Pós-graduação Ciências Veterinárias, Sanidade Animal, Universidade Federal Rural do Rio de Janeiro (UFRRJ), Seropédica, RJ, Brasil.

IIIMédico Veterinário, Autônomo, Rio de Janeiro, RJ, Brasil.

${ }^{\text {IV }}$ Departamento de Epidemiologia e Saúde Pública, UFRRJ, Seropédica, RJ, Brasil. 
1998), bubalinos (PAL, 1991), ovinos (SHNAWA \& NIGAM, 1987) e caprinos (CONTRERAS et al., 1995).

C. neoformans é cosmopolita, tem nicho ecológico restrito às áreas urbanas, prolifera no solo rico em excretas de aves e é um patógeno oportunista (BARÓ et al., 1998; CASWELL \& WILLIAMS, 2007; SEVERO et al., 1998). Em contrapartida, $\boldsymbol{C}$. gattii possui nicho ecológico rural, é sazonal, relacionado à floração dos eucaliptos (CASADEVALL \& PERFECT, 1998) e tende a desencadear a doença no hospedeiro imunocompetente, sendo caracterizado como patógeno primário (SEVERO et al., 1998). Geralmente, as infecções são esporádicas e ocasionais, mas alguns surtos epidêmicos têm sido descritos em grande número de animais (TORRES-RODRIGUEZ et al., 2006). Nos caprídeos, os relatos de criptococose pulmonar são raros e as principais alterações observadas são pleuropneumonia, congestão nasal, exsudato mucopurulento, dispneia, anorexia e caquexia (ALLER et al., 1971; BARÓ et al., 1998). A primeira descrição de criptococose pulmonar em cabras foi no Brasil (DACORSO \& CHAGAS, 1957) e, posteriormente, na Espanha (ALLER et al., 1971; BARÓ et al., 1998; GUTIÉRREZ \& MARÍN, 1999; GONZÁLEZ FERNÁNDEZet al., 2000; TORRES-RODRIGUEZ etal., 2006).

A linfadenite caseosa é causada pelo Corynebacterium pseudotuberculosis, bacilo Grampositivo, pleomórfico, aeróbio, que cresce em ágar sangue em 24-48 horas e causa hemólise (RIETCORREA et al, 2001). De acordo com PRESCOTT et al. (2002), C. pseudotuberculosis é uma bactéria distribuída mundialmente, que afeta ovinos e caprinos, além de desencadear infecções ocasionais em outras espécies. Sua evolução é crônica, de aparecimento esporádico com alterações caseopurulentas no pulmão e gânglios linfáticos (BEER, 1999). Abscessos rompidos contaminam camas e abrigos, resultando na permanência do micro-organismo por longo tempo no ambiente (CORRÊA \& CORRÊA, 1992). Lesões nas tonsilas e nos linfonodos retrofaríngeos de um animal doente podem ser responsáveis pela infecção aerógena de outros animais que estiverem em contato. Acreditase que a bactéria penetre no hospedeiro por via respiratória, percutânea ou digestiva, multiplica-se induzindo a formação de microabscessos e através da corrente linfática aferente chega aos linfonodos regionais onde os abscessos são formados (PUGH, 2002).

Descreve-se um caso de criptococose pulmonar, concomitante à infecção sistêmica por $\boldsymbol{C}$. pseudotuberculosis, em uma cabra (Capra hircus) da raça Saanen, com 10 anos de idade, atendida na
Policlínica da Universidade Estácio de Sá, proveniente do município de Itaguaí, RJ. O animal apresentava quadro clínico de apatia, anorexia, dispneia, prostração, edema submandibular, abscessos nas regiões supraescapular direita, coxofemoral e articulações tíbio-tarsometatársica e metatarso-falangeana do membro pélvico direito. A cabra morreu 30 minutos após sua chegada ao hospital. À necropsia, visualizou-se hidrotórax e hidropericárdio, áreas de consolidação do parênquima pulmonar e um grande abscesso de $10 \mathrm{~cm}$ no lobo caudal do pulmão esquerdo, com aderência na pleura parietal (Figura 1A). Havia também atrofia gelatinosa da gordura perirrenal, rins pálidos e fígado de coloração pálidoacastanhada, com numerosas áreas firmes, esbranquiçadas, medindo cerca de 1 a $2 \mathrm{~mm}$ de diâmetro. Os abscessos articulares drenavam pus denso de coloração amarelo-esverdeada. Observouse osteólise e osteoproliferação na escápula direita. Amostras de diversos tecidos foram coletadas, fixadas em formol a $10 \%$ tamponado, processadas para histopatologia, cortadas a $5 \mu \mathrm{m}$, e coradas pela hematoxilina-eosina e pelo ácido periódico de Schiff (PAS), no Setor de histopatologia da mesma universidade. Exsudato dos abscessos foi coletado para exame bacteriológico. A histopatologia do pulmão revelou atelectasia, edema alveolar, bronquiolite neutrofílica e infiltrado inflamatório mononuclear no interstício pulmonar; adjacente a essas regiões, verificou-se pleuropneumonia supurativa-necrotizante e fibrose. Havia leveduras em amostras de tecido pulmonar, circundadas por cápsulas espessas realçadas pela coloração do PAS (Figura 1B), sugerindo infecção por Cryptococcus spp. Junto a essas estruturas, a inflamação mononuclear era mínima, pouco significativa, como também descrito por GUTIÉRREZ \& GARCÍA MARÍN (1999) em um caso de pneumonia por $\boldsymbol{C}$. neoformans associado a Mycobacterium bovis em cabra. No fígado, havia atrofia de cordões de hepatócitos e deposição de material eosinofílico, hialino e fibrilar - "amiloide". O exame bacteriológico a partir de material purulento colhido dos abscessos articulares foi realizado pelo Centro Clínico e Apoio ao Diagnóstico Veterinário Labovet, Campo Grande, RJ, e revelou infecção por $\boldsymbol{C}$. pseudotuberculosis.

O diagnóstico de criptococose deu-se pela observação da morfologia típica do fungo que demonstrou, no exame histopatológico, células arredondadas com presença de cápsula polissacarídica (CASWELL \& WILLIAMS, 2007). Os sinais clínicos de apatia, anorexia, prostração e emaciação, somados à idade avançada da cabra e à infecção bacteriana sistêmica simultânea, sugerem um quadro clínico de baixa resistência orgânica e contaminação oportunista 


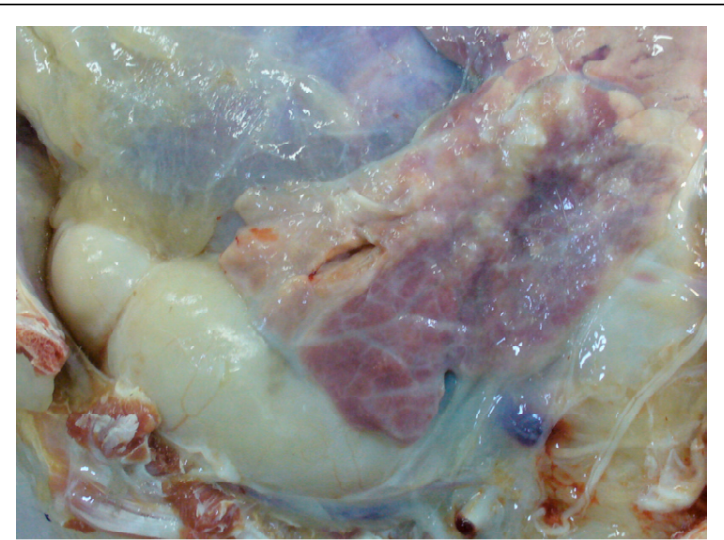

A

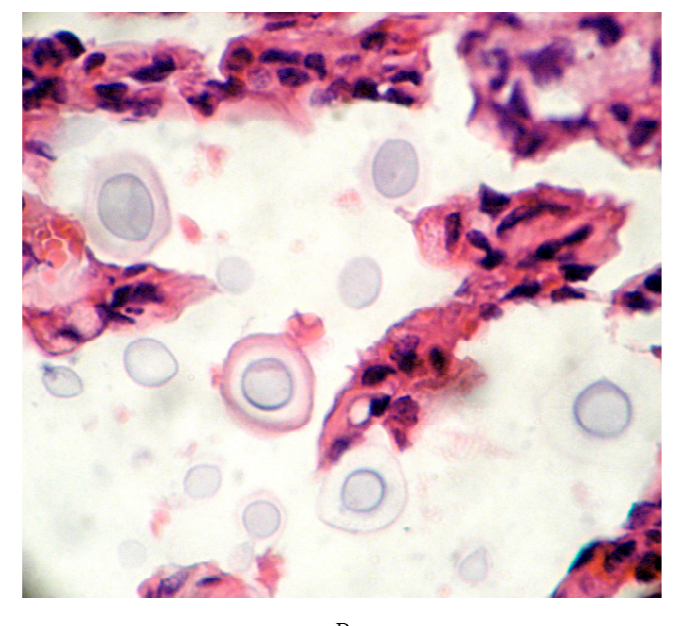

B

Figura 1 - A. Abcesso pulmonar com aderência na pleura parietal. B. Células leveduriformes circundadas por espessas cápsulas, no interior dos alvéolos pulmonares. HE, obj. 40.

por Cryptococcus spp., como citado por alguns autores (CASWELL \& WILLIAMS, 2007; KOMMERS, 2005). Além disso, os abscessos articulares e o acúmulo de amiloide no fígado da cabra, lesões também compatíveis com infecções crônicas sistêmicas, corroboram a tese de hiperestimulação seguida por exaustão do sistema imunológico e queda de resistência, o que facilitou a infecção secundária por Cryptococcus spp. Outra evidência que reforça a teoria da exaustão do sistema imunológico do hospedeiro é a ausência ou a ínfima reação inflamatória à presença de leveduras nos alvéolos pulmonares, em oposição ao que se deveria esperar em resposta à elevada patogenicidade da cápsula polissacarídica do fungo (JONES et al., 2000; CHANG \& KWON-CHUNG, 1994). Contudo, a diferenciação entre $\boldsymbol{C}$. gattii e $\boldsymbol{C}$. neoformans requer isolamento e cultivo em meios de cultura específicos ou técnicas moleculares, como, por exemplo, a técnica de Reação em Cadeia da Polimerase (PCR) (BIALEK et al., 2002; BARONI et al., 2006; CARVALHO et al., 2007).

$\mathrm{O}$ fato de encontrarmos leveduras apenas no pulmão da cabra sugere que a infecção tenha sido contraída por via aerógena, como também comentado por CASWELL \& WILLIAMS (2007) e TORRESRODRIGUEZ et al. (2006), já que outros tecidos não revelaram a presença de fungos. Essa teoria nos leva a descartar a possibilidade de contaminação pulmonar por via hematógena, e também de não haver tempo hábil para a disseminação do fungo. Outra questão pertinente é o fato de o animal ser oriundo de área rural rica em eucaliptos, dado compatível com a epidemiologia de $\boldsymbol{C}$. gattii.

Linfadenite caseosa e criptococose são enfermidades de distribuição mundial e amplamente estudadas, mas este é o primeiro relato dessas enfermidades acometendo o mesmo animal e o segundo relato de criptococose pulmonar em cabras, no Brasil.

\section{REFERÊNCIAS}

ALLER, B. et al. Cryptococosis pulmonar en cabras. Revista del Patronato de Biología Animal, v.XV, p.387-397, 1971.

BARÓ, T. et al. First identification of autochthonous Cryptococcus neoformans var. gatti isolated from goats with predominantly severe pulmonary disease in Spain. Journal of Clinical Microbiology, v.36, n.2, p.458-461, 1998. Disponível em: <http://www.ncbi.nlm.nih.gov/pmc/articles/ PMC104559/>. Acesso em: 26 abr. 2011.

BARONI, F.A. et al. Cryptococcus neoformans strains isolated from church towers in Rio de Janeiro City, RJ, Brazil. Revista do Instituto de Medicina Tropical de São Paulo, v.48, n.2, p.7175, 2006. Disponível em: <http://www.scielo.br/ scielo.php?pid=S0036-46652006000200003\&script=sci_arttext $>$. Acesso em: 26 abr. 2011. dói: 10.1590/5003646652006000200003.

BEER, J. Doenças infecciosas em animais domésticos. São Paulo: Roca, 1999. 394p. BERNARDO, F.M. et al. Fontes urbanas de Cryptococcus spp-Lisboa. Revista Portuguesa de Ciências Veterinárias, v.96, n.539, p.157-160, 2001. Disponível em: <http://www.fmv.utl.pt/spcv/PDF/pdf9_2001/ Fontes\%20Urbanas.pdf>. Acesso em: 26 abr. 2011.

BIALEK, R. et al. Detection of Cryptococcus neoformans DNA in Tissue Samples by Nested and Real-Time PCR Assays. Clinical and diagnostic laboratory immunology. American Society for Microbiology, v.9, n.2, p.461-469, 2002. Disponível em: 〈http://cvi.asm.org/cgi/content/short/9/2/461>. Acesso em: 26 abr. 2011. doi: 10.1128/CDLI.9.2.461-469.2002.

BIVANCO, F.C. et al. Criptococose cutânea. Arquivo Médico ABC, v.31, n.2, p.102-109, 2006. Disponível em: <http:// cvi.asm.org/cgi/content/full/9/2/461>. Acesso em: 26 abr. 2011. doi: 10.1128/CDLI.9.2.461-469.2002.

CARVALHO, V.G. et al. Serotype and mating type characterization of Cryptococcus neoformans by Multiplex 
PCR. Revista do Instituto de Medicina Tropical de São Paulo, v.49, n.4, p.207-210, 2007. Disponível em: <http:// w w w. s c i e 1 o.br/s c i e 1 o.ph p ? p i d = S 0036 $46652007000400002 \&$ script=sci_arttext $>$. Acesso em: 26 abr. 2011. doi: 10.1590/S0036-46652007000400002.

CASADEVALL, A.; PERFECT, J.R. Cryptococcus neoformans. Washington: American Society for Microbiology, 1998. 541p.

CASWELL, J.L.; WILLIAMS, K.J. The respiratory system. In: JUBB, K.V.F. et al. Pathology of domestic animals. 5.ed. Philadelphia: Saunders, 2007. V.2, cap.5, p.642-644.

CHANG, C.Y.; KWON CHUNG, K.J. Complementation of a capsule-deficient mutation of Cryptococcus neoformans restores its virulence. Molecular and Cellular Biology, v.14, n.7, p.4912-4919, 1994. Disponível em: <http://mcb.asm.org/cgi/ reprint/14/7/4912>. Acesso em: 26 abr. 2011.

CONTRERAS, A. et al. Prevalency and aetiology of non clinical intramammary infection in Murciano-Granadina goats. Small Ruminant Research, v.17, p.71-78, 1975.

CORREA, W.M.; CORREA, C.N.M. Enfermidades infecciosas dos mamíferos domésticos. Rio de Janeiro: Medsi, 1992. 843p.

DACORSO, P.F.; CHAGAS, W.A. Criptococose pulmonar em caprino. Anais do Colégio Anatômico Brasileiro, v.3, p.5569, 1957.

GONZÁLEZ FERNÁNDEZ, J. et al. Criptococosis pulmonar em cabras. Patología Animal, v.XXV, Comunicación 26, 2000 .

GUTIÉRREZ, M.; GARCÍA MARÍN, J.F. Cryptococcus neoformans and Mycobacterium bovis causing granulomatous pneumonia in a goat. Veterinary Pathology, v.36, p.445 448, 1999. Disponível em: <http://vet.sagepub.com/content/ 36/5/445.full.pdf+html>. Acesso em: 26 abr. 2011. doi: 10.1354/ vp. 36-5-445.

JONES, T.C. et al. Patologia veterinária. São Paulo: Manole, 2000. Cap.10, p.489-491. Cap. 11, p.526-528.

KOMMERS, G.D. et al. Criptococose pulmonary granulomatosa em um equino. Ciência Rural, v.35, n.4, p.938-940, 2005. Disponível em: <http://www.scielo.br/scielo.php?script=sci_arttext\&pid=S010384782005000400032>. Acesso em: 26 abr. 2011. doi: 10.1590/S010384782005000400032 .
LANGONI, H. et al. Participação de leveduras, algas e fungos na mastite bovina. Veterinária e Zootecnia, v.10, p.89-98, 1998.

LIN, X. Cryptococcus neoformans: morphogenesis, infection, and evolution. Infection, Genetics and Evolution, v.9, p.401416, 2009. Disponível em: <http://www.ncbi.nlm.nih.gov/pubmed/ 19460306>. Acesso em: 26 abr. 2011. doi: 10.1016/ j.meegid.2009.01.013

PAL, M. Mastitis in a water buffalo (Bubalus bubalis) due to Cryptococcus neoformans var. neoformans. Revista Iberoamericana de Micologia, v.8, p.89-91, 1991. Disponível em: $\langle$ http://cat.inist.fr/?aModele $=$ afficheN\&cpsidt=5192941〉. Acesso em: 26 abr. 2011.

PAPPALARDO, M.C.S.M.; MELHEM, M.S.C. Criptococcose: revisão sobre a experiência brasileira sobre a doença. Revista do Instituto de Medicina Tropical de São Paulo, v.45, n.6, p.299-305, 2003. Disponível em: <http://www.scielo.br/pdf/ rimtsp/v45n6/18587.pdf>. Acesso em: 26 abr; 2-11.

PUGH, D.G. Sheep e goat medicine. Philadelphia: Saunders, 2002. 468p.

PRESCOTT, J.F. et al. An inferferon-gamma assay for diagnosis of Corynebacterium pseudotuberculosis infection um adult sheep from a research flock. Veterinary Microbiology, v.88, p.287-297, 2002. Disponível em: <http://www.ncbi.nlm.nih.gov/pubmed/12151202>. Acesso em: 26 abr. 2011. doi: 10.1016/j.vetmic.2007.10.013.

RIET-CORREA, F. et al. Doenças de ruminantes e eqüinos. São Paulo: Varela, 2001. 999p..

SEVERO, L.C. et al. Diferenças clínicas, epidemiológicas e ecológicas entre as duas variedades de Cryptococcus neoformans. Revista Médica da Santa Casa, v.9, n.16, p.1672-1686, 1998.

SHNAWA, I.M.S.; NIGAM, J.M. A note on cryptococcal mastitis in sheep. Indian Veterinary Medical Journal, v.7, p.175176, 1987.

TORRES-RODRIGUEZ, J.M. et al. Cryptococcosis by Cryptococcus gattii in immunocompetent goats in Spain and review of the literature. Acta Scientiae Veterinariae, v.34, n.3, p.245-253, 2006. Disponível em: <http://www.ufrgs.br/ actavet/34-3/artigo683.pdf>. Acesso em: 26 abr. 2011. 